\title{
The Catecholamine Response to Hypoglycemia in Children with Isolated Growth Hormone Deficiency Syndromes and Multiple Pituitary Hormone Defects
}

\author{
STUART A. CHALEW AND A. AVINOAM KOWARSKI \\ Department of Pediatrics, University of Maryland School of Medicine, Baltimore, Maryland 21201
}

\begin{abstract}
We examined the catecholamine response to insulin-induced hypoglycemia in $\mathbf{4 6}$ short children evaluated for growth hormone (GH) deficiency by both pharmacologic stimulation and integrated concentration of GH. Twelve patients had quantitatively normal GH secretion by both pharmacologic stimulation and integrated concentration of GH (GHNORM). Twenty-two patients had normal GH to pharmacologic stimulation but subnormal integrated concentration of GH (GHND). Twelve patients had GH deficiency by both tests (GHD): six had isolated GH deficiency (GHD type 1) and six had multiple hormone deficiencies (GHD type 2). There was no significant difference between the peak epinephrine, norepinephrine, and cortisol responses of GH-NORM, GHND, and GHD type 1 patients. The mean peak epinephrine response of GHD type 2 patients was significantly lower $(564 \pm 561 \mathrm{pg} / \mathrm{ml}$, $p<0.03$ ) compared to the other patient groups. There was no significant difference between the peak norepinephrine levels between GHD type 2 patients and the remaining groups. There was no correlation between decrease in blood glucose and either increase in growth hormone, catecholamine, or cortisol concentrations. There was a significant correlation between log peak epinephrine and peak cortisol response $(r=0.53, p<0.0002)$ of the 46 subjects. Neither the basal nor stimulated catecholamine levels correlated with the integrated concentration of cortisol. We conclude that 1 ) isolated GH deficiency is not associated with impairment of the catecholamine response to hypoglycemia; 2) impairment of the epinephrine response to hypoglycemia is only associated with multiple pituitary hormone deficiencies; 3 ) in children, the degree of glucose lowering is not correlated with the magnitude of peak $\mathbf{G H}$, catecholamine, or cortisol responses. (Pediatr Res 20: 1097-1101, 1986)
\end{abstract}

\section{Abbreviations}

IC-GH, integrated concentration of growth hormone IC-cortisol, integrated concentration of cortisol GH, growth hormone

GHD, patients with growth hormone deficiency by stimulation tests and IC-GH

GHND, patients with normal growth hormone secretion to pharmacologic stimuli but deficient GH secretion by ICGH

Received March 20, 1986; accepted June 4, 1986.

Correspondence to A. Avinoam Kowarski, M.D., University of Maryland School of Medicine, Bressler Research Building, Room 10-047. Baltimore, MD 21201 Supported in part by Research Grant HD-16077, National Institutes of Health, USPHS.
GH-NORM, patients with normal quantitative growth hormone levels by stimulation and IC-GH

Although assessment of the $\mathrm{GH}$ response to pharmacologic stimuli is an established technique for diagnosis of GH deficiency (1), stimulation tests may not adequately characterize a patient's spontaneous GH secretion. Constant withdrawal methodology for measuring the IC-GH allows measurement of a subject's average spontaneous $\mathrm{GH}$ concentration $(2,3)$. Our group has shown previously that the $\mathrm{GH}$ response to pharmacologic stimulation may be discordant with the IC-GH $(4,5)$. As many as $45 \%$ of short, poorly growing children have deficient spontaneous secretion of $\mathrm{GH}$ as measured by IC-GH despite normal $\mathrm{GH}$ responses to pharmacologic stimulation tests (5). Spiliotis et al. (6) have suggested that impaired $\mathrm{GH}$ secretion in such cases may be due to a defective GH secretory mechanism in the central nervous system above the pituitary, and they termed the disorder growth hormone neurosecretory dysfunction (6). However, the mechanism responsible for the disorder has not been established.

It has been reported that children with isolated deficient $\mathrm{GH}$ responses to pharmacologic stimulation tests (7) have impaired catecholamine secretion in response to hypoglycemia. On this basis, it has been suggested that noradrenergic dysfunction may contribute to the impaired release of $\mathrm{GH}$ in these patients (7). We therefore speculated that catecholamine secretory dysfunction also may be associated with GHND. Thus, we examined the catecholamine responses to hypoglycemia in short children with quantitatively normal GH secretion compared to patients with various defects in $\mathrm{GH}$ by pharmacologic and physiologic tests of GH secretion. We also studied the relationship of ICcortisol with catecholamine secretion in these subjects.

\section{METHODS}

Subjects. Patients in the study included those evaluated for short stature (height $\leq 5 \%$ for age and sex) or poor linear growth after nonendocrine disorders of growth failure had been ruled out. Patients with Turner's syndrome or other genetic abnormalities were excluded from this study. All patients were euthyroid at the time of study. No patient was receiving medication that would interfere with hormone secretion.

Study protocol. All diagnostic procedures were conducted in the Endocrine Diagnostic Unit at the University of Maryland. Each patient underwent a pharmacologic stimulation test for $\mathrm{GH}$ as well as a physiologic assessment of $\mathrm{GH}$ secretion by IC$\mathrm{GH}$.

GH stimulation testing. After an overnight fast, growth hormone secretion was evaluated in response to insulin-induced 
hypoglycemia ( 8 ) followed by a second stimulus, either arginine (8) or clonidine (9). During insulin-induced hypoglycemia, blood glucose levels were followed in real time using a continuous glucose monitor $(10,11)$. Blood samples for $\mathrm{GH}$, epinephrine, norepinephrine, and cortisol were drawn at baseline, $20 \mathrm{~min}$, at the true glucose nadir identified in real time, and at 10- and 20min after the glucose nadir (11). A normal GH response to paired stimulation was considered $\geq 10 \mathrm{ng} / \mathrm{ml}$. The maximum or peak level of $\mathrm{GH}$, epinephrine, and cortisol from each patient in response to stimulation was chosen for comparison with basal levels (11).

Integrated hormone concentration. Each patient also had a 20$24 \mathrm{~h}$ IC-GH assessment using constant blood withdrawal methodology (2-5). A nonthrombogenic catheter (Cormed, Medina, NY) was introduced into a large peripheral vein. Blood was withdrawn into a collection tube at a constant rate by a small withdrawal pump. The collection tubes were replaced every 30 min. A small aliquot was taken from each collection tube to form a pool from which the IC-GH was measured. The ICcortisol from 43 patients also was evaluated from the pooled sample (12). The reported range of IC-GH in children of normal stature was $3.2-11.5 \mathrm{ng} / \mathrm{ml}(5,13)$.

Assay techniques. Plasma $\mathrm{GH}$ was assayed using a standard double antibody technique (14). Plasma cortisol was assayed using a competitive protein binding method (15). Epinephrine and norepinephrine were assayed by a radioenzymatic technique $(16,17)$.

Statistical analysis. Differences in the mean values of variables between the different diagnostic groups were evaluated by analysis of variance and multiple comparison of means in a general linear model (18). The statistical effect of glucose nadir, fall in glucose, and other independent variables possibly having an effect on hormonal response were evaluated by a multivariate regression and by analysis of variance (18). Logarithmic transformation of data was performed where appropriate prior to statistical analysis to reduce the heterogeneity of variance between groups.

\section{RESULTS}

Diagnostic classification of patients. Patients were classified according to the results of their $\mathrm{GH}$ diagnostic tests.

GH-NORM. Twelve patients who had both a normal growth response to stimulation and normal IC-GH.

GHND. Twenty-two children who had a normal GH response to stimulation, but subnormal IC-GH.

$G H D$. Twelve children had subnormal GH secretion during both the GH stimulation test and IC-GH. These patients were further subdivided into six patients with isolated GH deficiency (GHD type 1) and six with multiple pituitary hormone deficiencies (GHD type 2 ).

Table 1 contains the mean values for age, bone age, height, weight, and body mass index for the patient groups. There were no statistically significant differences in these variables between groups.

Glucose response to insulin. Table 2 contains the mean \pm 1

Table 1. Age, bone age, $h t, w t$, and body mass index for the four groups (mean $\pm 1 S D$ )

\begin{tabular}{|c|c|c|c|c|}
\hline \multirow[b]{2}{*}{ Diagnostic group } & \multirow[b]{2}{*}{ GH-NORM } & \multirow[b]{2}{*}{ GHND } & \multicolumn{2}{|c|}{ GHD } \\
\hline & & & $\begin{array}{c}\text { Isolated GH } \\
\text { deficiency } \\
\text { (type 1) }\end{array}$ & $\begin{array}{l}\text { Multiple hormone } \\
\text { deficiency (type 2) }\end{array}$ \\
\hline Age $(y r)$ & $12 \pm 3$ & $11 \pm 3$ & $13 \pm 4$ & $11 \pm 3$ \\
\hline Bone age (yr) & $9 \pm 2$ & $8 \pm 3$ & $10 \pm 4$ & $9 \pm 3$ \\
\hline $\mathrm{Ht}(\mathrm{cm})$ & $131 \pm 14$ & $126 \pm 16$ & $127 \pm 17$ & $130 \pm 16$ \\
\hline Wt $(\mathrm{kg})$ & $29 \pm 7$ & $26 \pm 8$ & $31 \pm 14$ & $29 \pm 14$ \\
\hline Body mass index $\left(\mathrm{kg} / \mathrm{m}^{2}\right)$ & $17 \pm 2$ & $16 \pm 2$ & $18 \pm 4$ & $16 \pm 4$ \\
\hline
\end{tabular}

Table 2. Basal levels and response to insulin by diagnostic category (mean $\pm 1 S D$ )

\begin{tabular}{|c|c|c|c|c|}
\hline \multirow[b]{2}{*}{ Diagnostic group } & \multirow[b]{2}{*}{ GH-NORM } & \multirow[b]{2}{*}{ GHND } & \multicolumn{2}{|c|}{ GHD } \\
\hline & & & $\begin{array}{c}\text { Isolated GH } \\
\text { deficiency } \\
\text { (type 1) }\end{array}$ & $\begin{array}{l}\text { Multiple hormone } \\
\text { deficiency (type 2) }\end{array}$ \\
\hline$n$ & 12 & 22 & 6 & 6 \\
\hline Basal glucose (mg/dl) & $93 \pm 10$ & $86 \pm 10$ & $85 \pm 4$ & $81 \pm 9^{*}$ \\
\hline Glucose nadir (mg/dl) & $38 \pm 10$ & $40 \pm 11$ & $39 \pm 9$ & $43 \pm 7$ \\
\hline Basal GH $(\mathrm{ng} / \mathrm{ml})$ & $10 \pm 10$ & $5 \pm 7$ & $3 \pm 2$ & $2 \pm 2$ \\
\hline Peak GH $(\mathrm{ng} / \mathrm{ml})$ response to insulin & $15 \pm 10$ & $14 \pm 8$ & $4 \pm 2$ & $4 \pm 3$ \\
\hline $\begin{array}{l}\text { Peak } \mathrm{GH}(\mathrm{ng} / \mathrm{ml}) \text { response to second } \\
\text { stimuli }\end{array}$ & $15 \pm 4$ & $15 \pm 7$ & $5 \pm 2$ & $3 \pm 3$ \\
\hline Basal epinephrine response $(\mathrm{pg} / \mathrm{ml})$ & $85 \pm 37$ & $77 \pm 98$ & $54 \pm 37$ & $56 \pm 45$ \\
\hline Peak epinephrine response $(\mathrm{pg} / \mathrm{ml})$ & $1275 \pm 640$ & $971 \pm 687$ & $1484 \pm 898$ & $564 \pm 561 \dagger$ \\
\hline $\begin{array}{l}\text { Basal norepinephrine response (pg/ } \\
\text { ml) }\end{array}$ & $250 \pm 140$ & $213 \pm 47$ & $158 \pm 54 \ddagger$ & $289 \pm 87$ \\
\hline $\begin{array}{l}\text { Peak norepinephrine response (pg/ } \\
\mathrm{ml} \text { ) }\end{array}$ & $422 \pm 161$ & $349 \pm 111$ & $357 \pm 115$ & $364 \pm 102$ \\
\hline Basal cortisol (mcg/dl) & $17 \pm 6$ & $12 \pm 6$ & $11 \pm 8$ & $7 \pm 6$ \\
\hline Peak cortisol $(\mathrm{mcg} / \mathrm{dl})$ & $22 \pm 4$ & $19 \pm 5$ & $20 \pm 4$ & $7 \pm 6$ \\
\hline IC-cortisol (mcg/dl) & $9 \pm 3(11) \|$ & $7 \pm 2(20) \|$ & $6 \pm 2$ & $4 \pm 3 \S$ \\
\hline $\mathrm{IC}-\mathrm{GH}(\mathrm{ng} / \mathrm{ml})$ & $5.4 \pm 2.2$ & $1.9 \pm 0.6$ & $1.5 \pm 0.7$ & $1.4 \pm 0.9$ \\
\hline
\end{tabular}

* Difference significant from GH-NORM group $(p<0.02)$ only.

$\dagger$ Difference significant at $p<0.03$ compared to other groups.

$\$$ Difference significant compared to other groups $(p<0.05)$.

$\S$ Difference significant compared to GH-NORM $(p<0.0004)$ and to GHND $(p<0.02)$ groups.

\|l Parentheses contain number of patients if different from number at head of column. 
SD for hormone and glucose levels in response to insulin-induced hypoglycemia, as well as the IC-GH and IC-cortisol values for each group. The mean glucose nadir and time required to reach the nadir were not significantly different in the four groups. Due to a lower basal glucose level, the percent fall in the nadir glucose level was significantly smaller in GHD type 2 patients only when they were compared with the GH-NORM group $(p<0.02)$.

Hormonal responses. There was no statistical difference between the peak GH response to insulin or the second stimulus in GH-NORM and GHND subjects. There were no statistical differences in $\mathrm{GH}$ responses to stimuli in the two GH-deficient groups.

The mean peak epinephrine level of GHD type 2 patients was significantly lower than the responses of the other groups $(p<$ 0.03 ). There were no statistically significant differences between the mean peak epinephrine levels of the GH-NORM, GHND, and GHD type 1 groups. Individual peak epinephrine levels are depicted by group in Figure 1. Although the mean basal epinephrine level of GHD patients was lower in comparison to the other groups, this difference did not attain statistical significance.

There were no statistically significant differences in the mean peak norepinephrine levels between groups. Individual peak norepinephrine levels are shown in Figure 2. The basal norepinephrine levels of GHD type 1 patients were significantly lower than in the other groups $(p<0.05)$.

There was no correlation between the $\mathrm{GH}$ response to insulin or to the second stimulus and the catecholamine response to hypoglycemia. There was no correlation between the norepinephrine response to hypoglycemia and the IC-GH value. However, a weak but statistically significant $(r=0.33, p<0.03)$ correlation was found between the peak epinephrine response and the IC-GH.

Due to the patient classification criteria, there were statistically significant differences in the basal and peak cortisol levels of the GHD type 2 group and the other groups. The IC-cortisol result for the GHD type 2 patients was significantly lower than that of the GH-NORM $(p<0.0004)$ and GHND $(p<0.02)$ patients but not from the other GHD type 1 patients. There was a significant correlation between the peak cortisol response to hypoglycemia and both the peak $\mathrm{GH}$ response to hypoglycemia

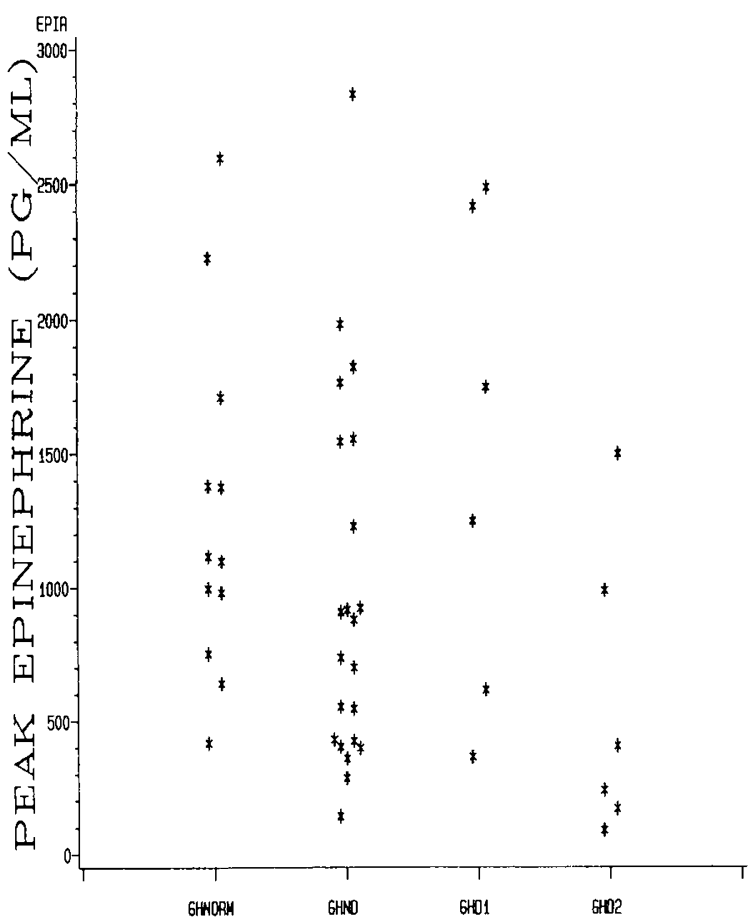

Fig. 1. Peak epinephrine responses to insulin-induced hypoglycemia in individual patients classified by group.

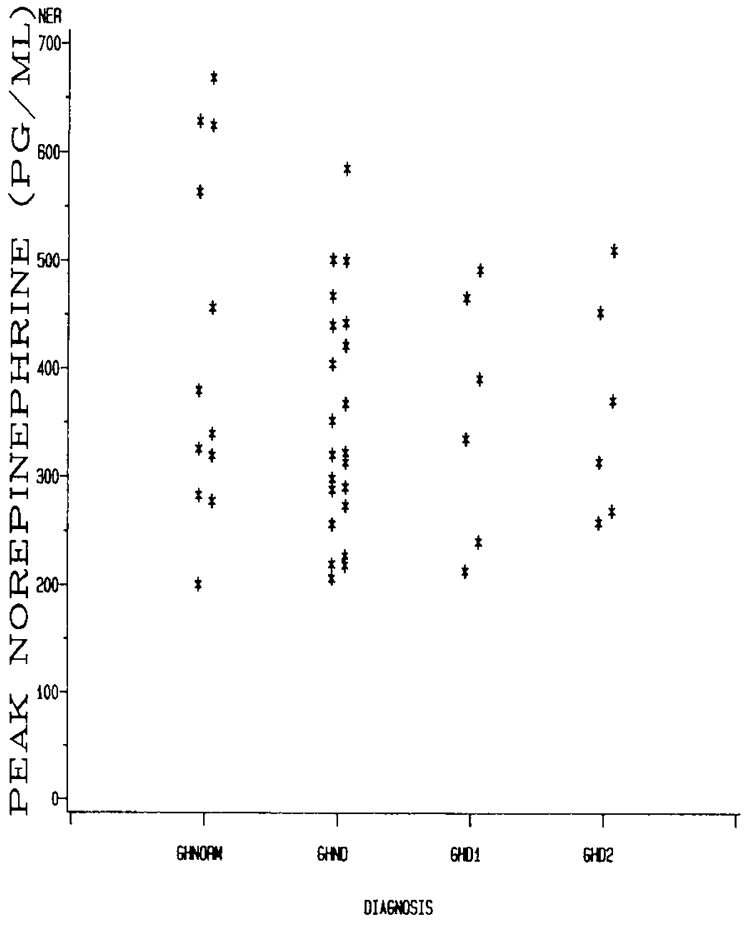

Fig. 2. Peak norepinephrine response to insulin-induced hypoglycemia in individual patients classified by group.

( $r=0.33, p<0.03)$ and the peak $\mathrm{GH}$ response to the second stimulus $(r=0.42, p=0.006)$.

There was no statistically significant correlation between either the fall in glucose level or the absolute glucose nadir levels and the peak catecholamine (or log peak catecholamine) response or percent rise in catecholamine level above baseline. These conditions were tested with and without statistical control of diagnostic group. The log peak epinephrine level versus glucose nadir level is depicted in Figure 3 by diagnostic groups. There was no correlation between the peak cortisol response and either the glucose nadir, fall in glucose from baseline, or percent fall in glucose. There was no correlation between the $\mathrm{GH}$ response to hypoglycemia and the glucose nadir level.

There were statistically significant correlations between the peak cortisol level and the natural log basal epinephrine $(r=$ $0.45, p<0.002)$, or the natural log peak epinephrine $(r=0.53$, $p<0.0002)$. There were no significant correlations between the peak cortisol and basal or peak norepinephrine levels. There were no correlations between the IC-cortisol values and the catecholamine levels either basal or stimulated.

\section{DISCUSSION}

One of the objectives of this study was to determine whether GH deficiency in GHND patients was associated with defective catecholamine secretion. We found no difference in the peak epinephrine and norepinephrine responses of GHND patients compared with patients having intact $\mathrm{GH}$ secretion. In addition, patients who had isolated $\mathrm{GH}$ deficiency by both stimulation tests and IC-GH measurement had no difference in peak catecholamine secretion in response to hypoglycemia compared to patients with intact GH secretion or GHND. Only patients with multiple deficits of pituitary hormone secretion had a statistically significant impairment of the peak epinephrine response, but not of the norepinephrine response to hypoglycemia.

Our findings in patients with isolated $\mathrm{GH}$ deficiency conflict with the results of a previous study by Voorhess and MacGillivray (7). They reported a statistically significant impairment of the plasma norepinephrine and epinephrine responses to hypoglycemia in eight patients with isolated GH deficiency (7) as measured by pharmacologic stimulation tests. 


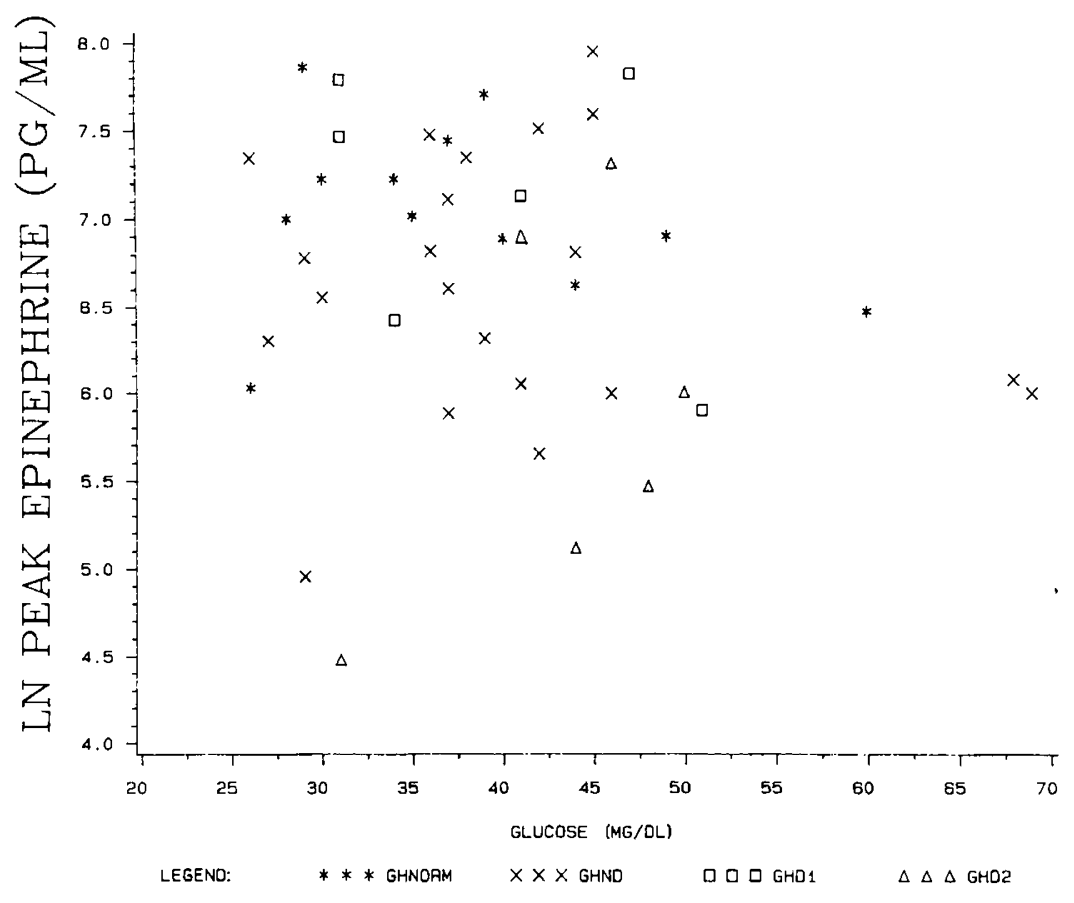

Fig. 3. Natural log of the peak epinephrine response to the glucose nadir for individual patients classified by group.

The data from the present study indicate that there is no difference in peak catecholamine secretion in children with GHND compared to children with normal GH secretion or patients with isolated $\mathrm{GH}$ deficiency diagnosed by stimulation testing. Thus defective catecholamine secretion, at least as reflected by plasma epinephrine and norepinephrine levels, is not an etiologic factor in isolated $\mathrm{GH}$ deficiency syndromes. In a previous study we showed that there was no difference in the peak $\mathrm{GH}$ response to GH-releasing hormone in GHND children compared to normal GH secretors (19), and although the GH response to GH-releasing hormone of classically GH-deficient children was significantly lower than the responses of either GHND children or normal GH secretors, there was considerable overlap in the range of the three groups (19). At present, the IC$\mathrm{GH}$ assessment remains the best diagnostic method for identification of GHND. The underlying pathophysiology of GHND remains unexplained.

Rudman et al. (20) reported a $80-90 \%$ reduction of epinephrine levels both at rest and in response to exercise stimulation only in patients with hypocorticotropic hypopituitarism. They found no difference between groups in either the resting or stimulated levels of norepinephrine. They suggested that the lower epinephrine levels in hypocorticotropic hypopituitary patients may have been the result of impaired adrenomedullary enzymatic synthesis of epinephrine (20). In the present study we found the basal mean epinephrine level of GH-NORM patients was above the mean epinephrine concentration of GHND, which was in turn above the mean level of epinephrine in GHD type 1 and type 2. The mean basal epinephrine levels of GHD type 1 and type 2 patients were similar. Although the differences in epinephrine levels between groups did not attain statistical significance in our analysis, the trend in the data agrees with the findings of Rudman et al. (20).

It has been proposed that cortisol secretion is necessary to induce the enzyme phenylethanolamine $\mathrm{N}$-methyl transferase in the adrenal medulla; this enzyme catalyzes conversion of norepinephrine to epinephrine. We examined the relationship of spontaneous cortisol secretion on the catecholamine response to hypoglycemia. The 24-h IC-cortisol reflects the average cortisol concentration during a 24-h period. We found no correlation of the IC-cortisol with either basal- or peak-stimulated epinephrine levels. This observation suggests that epinephrine release in response to hypoglycemia can occur at very low levels of spontaneous ACTH and cortisol secretion as reflected by IC-cortisol levels. In particular, two GHD type 2 patients with very low ICcortisol levels had stimulated epinephrine responses well within the normal range.

There was a significant correlation between the log peak epinephrine response and the peak cortisol response to insulininduced hypoglycemia. The correlation between the peak epinephrine and cortisol responses may indicate that lowering blood glucose leads to a stimulation of a common central release mechanism for these hormones. We speculate that damage to a common secretory area might impair the release of both epinephrine and cortisol. The lower epinephrine responses of patients with multiple pituitary hormone deficiencies may be due to CNS dysfunction involving both pituitary hormone and epinephrine secretory mechanisms. Although intracranial lesions can lead to severe impairment of GH and cortisol secretion and to deficiencies of other pituitary hormones, a normal epinephrine response to hypoglycemia may be preserved. For example, one GHD type 2 patient had panyhypopituitarism and diabetes insipidus after treatment for a craniopharyngioma, yet she had an enhanced peak epinephrine response.

The magnitude of the $\mathrm{GH}$, epinephrine, norepinephrine, and cortisol responses to hypoglycemia has been reported as primarily an inverse function of the absolute plasma glucose concentration $(21,22)$. However, in short children, we found considerable individual variation of the $\mathrm{GH}$, catecholamine, and cortisol responses at any absolute glucose level. There was no correlation between the magnitude of the catecholamine or cortisol responses and the degree of hypoglycemia induced by insulin, regardless of diagnostic group. The threshold for release and the magnitude of epinephrine, norepinephrine, cortisol, and $\mathrm{GH}$ responses to glucose lowering are highly variable in childhood.

Acknowledgments. The authors thank Jackie Newhouse, Teresa Palese, and Baiba Pironis for their assistance in the hormonal assays and Barbara S. Mace for preparation of the manuscript. We also acknowledge the valuable contribution of Debra Pitarra who conducted stimulation tests and constant withdrawal studies. 


\section{REFERENCES}

1. Frasier SD 1973 Growth hormone stimulation tests in children. In: Raiti S (ed) Advances in Human Growth Hormone Research, USDHEW Publication no (NIH)74-612

2. Kowarski AA. Thompson RG, Migeon CJ, Blizzard RM 1971 Determination of integrated concentration of true secretion rate of human growth hormone. J Clin Endocrinol Metab 32:356-360

3. Plotnick LP. Thompson RG, Kowarski AA deLacerda L, Migeon CJ, Blizzard RM 1975 Circadian variation of integrated concentration of growth hormone in children and adults. J Clin Endocrinol Metab 40:240-247

4. Plotnick LP, Lee PA, Migeon CJ, Kowarski AA 1979 Comparison of physiologic and pharmacological tests for growth hormone function in children with short stature. J Clin Endocrinol Metab 48:811-815

5. Zadik Z. Chalew SA. Raiti S, Kowarski AA 1985 Do short children secrete insufficient growth hormone? Pediatrics 76:355-360

6. Spiliotis BE, August GP. Hung W. Sonis W. Mendelson W, Bercu BB 1984 Growth hormone neurosecretory dysfunction: a treatable cause of short stature. JAMA 251:2223-2230

7. Voorhess ML, MacGillivray MH 1984 Low plasma norepinephrine responses to acute hypoglycemia in children with isolated growth hormone deficiency. J Clin Endocrinol Metab 59:790-793

8. Raiti S. Davis WT. Blizzard RM 1982 A comparison of the effects of insulin hypoglycemia and arginine infusion on the release of human growth hormone. Lancet 2:1182-1183

9. Lanes R, Hurtado E 1982 Oral clonidine-an effective growth hormone releasing agent in prepubertal subjects. J Pediatr 100:710-714

10. Hadji-Georgopoulos A, Schmidt MI, Margolis S, Kowarski AA 1980 Elevated hypoglycemic index and late hyperinsulinism in symptomatic postprandial hypoglycemia. J Clin Endocrinol Metab 50:371-376

11. Chalew SA, McLaughlin JV, Mersey JH, Adams AJ, Cornblath M, Kowarski AA 1984 The use of the plasma epinephrine response in the diagnosis of idiopathic postprandial syndrome. JAMA 251:612-615

12. Zadik Z, deLacerda L, Kowarski AA 1982 Evaluation of the 6 hour integrated concentration of cortisol as a diagnostic procedure for Cushing syndrome. $J$ Clin Endocrinol Metab 54:1072-1074

13. Zadik Z, Chalew SA, McCarter RJ Jr, Meistas M, Kowarski AA 1985 The influence of age on the 24-hour integrated concentration of growth hormone in normal individuals. J Clin Endocrinol Metab 60:513-516

14. Schalch DS, Parker ML 1964 A sensitive double antibody immunoassay for human growth hormone in plasma. Nature 203:1141-1145

15. Beitins IZ, Shaw MH, Kowarski AA, Migeon CJ 1970 Comparison of com petitive protein binding radioassay of cortisol to double isotope dilution and Porter-Silber methods. Steroids 15:765-776

16. Peuler JD, Johnson GA 1977 Simultaneous single isotope radioenzymatic assay of plasma norepinephrine, epinephrine and dopamine. Life Sci 21:625

17. Passon PG, Johnson GA 1973 A simplified radiometric assay for plasma norepinephrine and epinephrine. Anal Biochem 51:618

18. Ray AA 1982 SAS User's Guide: Statistics. SAS Institute, Cary, NC

19. Chalew SA, Armour KM, Levin PA, Thorner MO, Kowarski AA 1986 Growth hormone response to GHRH in children with subnormal integrated concentrations of growth hormone. J Clin Endocrinol Metab 62:1110.

20. Rudman D, Moffitt SD, Fernhoff PM, Blackston RD, Faras BA 1981 Epinephrine deficiency in hypocorticotropic hypopituitary children. $\mathrm{J}$ Clin Endocrinol Metab 53:722-729

21. Cryer PE 1981 Glucose counterregulation in man. Diabetes 30:261-264

22. Christensen NJ, Alberti KGMM, Brandsborg O 1975 Plasma catecholamines and blood substrate concentrations: studies in insulin induced hypoglycemia and after adrenaline infusions. Eur $\mathbf{J}$ Clin Invest 5:415-423 